\title{
EFFECTS OF THE DOPING LEVEL IN THE PRODUCTION OF SILICON NANOWALLS BY METAL ASSISTED CHEMICAL ETCHING
}

\author{
Viridiana Aca-López ${ }^{1}$,Enrique Quiroga-González ${ }^{2 *}$,Estela Gómez-Barojas ${ }^{1}$, Jolanta \\ Światowska ${ }^{3}$, J. Alberto Luna-López ${ }^{1}$ \\ ${ }^{1}$ CIDS-IC, Benemérita Universidad Autónoma de Puebla. PO Box 196, 72000 Puebla, Mexico. \\ ${ }^{2}$ Institute of Physics, Benemérita Universidad Autónoma de Puebla. PO Box J-48, 72570 Puebla, Mexico. \\ ${ }^{3}$ Chimie ParisTech-CNRS, PSL Research University, Institut de Recherche de Chimie Paris (IRCP), \\ Physical Chemistry of Surfaces Group, 11 rue Pierre et Marie Curie, 75005 Paris, France.
}

*equiroga@ieee.org

\begin{abstract}
Si nanowalls have been prepared out of Si substrates in a wide range of resistivities, by Metal Assisted Chemical Etching (MACE). Si (100) boron doped wafers with three resistivities 15-25 $\Omega \cdot \mathrm{cm}, 0.01-0.02 \Omega \cdot \mathrm{cm}$ and 0.0005-0.0007 $\Omega \cdot \mathrm{cm}$ were used in this work. MACE was carried out in two steps: first, silver particles were deposited; and second, the etching solutions were optimized by varying the $\mathrm{HF}$ and $\mathrm{H}_{2} \mathrm{O}_{2}$ concentrations. This is the first time that nanowalls are obtained out of substrates of resistivity smaller than $0.001 \Omega \cdot \mathrm{cm}$. The relation of sizes and characteristics of the walls with the doping level of the Si substrates has been emphasized.
\end{abstract}

\section{Keywords: Si etching, metal assisted chemical etching, nanowalls, Ag chemical deposition}

\section{Introduction}

Semiconductor nanostructures have proven to be good candidates for the development of low dimensional devices. They have gained great interest in the scientific community due to the improvements in operation and manufacturing of some optoelectronic devices [1], biosensors [2], energy storage devices [3], and also their use as sacrificial layers in micromachining [4, 5]. Si nanostructures have been obtained mainly by two fabrication techniques. First, a top-down approach based on silicon wafer processing by means of high resolution lithography and dry or wet etching [6-9], and the conventional lithography techniques that offer great flexibility and precision in device positioning, but the fabrication of nanowires with high-aspect ratio has to be improved. Second, a bottom-up approach based on the vapor-liquid-solid deposition (VLS) growth by means of chemical-vapor deposition with $\mathrm{SiH}_{4}$ or $\mathrm{SiCl}_{4}$ as precursor and $\mathrm{Au}$ nanoparticles as catalysts [10-12]. Both of these techniques are expensive. An alternative top-down approach is the electrochemical etching of $\mathrm{Si}$ in solutions containing hydrofluoric acid (HF), which allows the fabrication of silicon structures like luminescent porous silicon and silicon nanowires [13, 14]. Taking this method as base, an even simpler method was developed, called metal assisted chemical etching (MACE). This method is a relatively simple and effective top-down technique to obtain nanowalls and nanowires of $\mathrm{Si}$. It uses a noble metal such as $\mathrm{Ag}$, $\mathrm{Au}$ or $\mathrm{Pt}$ as catalyst to etch $\mathrm{Si}$. MACE can be performed either in one or two successive steps. The first step consists on the 
deposition of a noble metal on the Si substrate and the second step on the immersion of Si wafer into the etching solution composed of $\mathrm{HF}$ and hydrogen peroxide $\left(\mathrm{H}_{2} \mathrm{O}_{2}\right)$ as the usual oxidant agent. Other oxidant reactants can be: iron (III) nitrate $\left(\mathrm{Fe}\left(\mathrm{NO}_{3}\right)_{3}\right)$ [15] or potassium permanganate $\left(\mathrm{KMnO}_{4}\right)$ [16].

Different techniques can be used to deposit the noble metals on semiconductors to enable the MACE process, such as: sputtering [17], spin-coating [18] and the electroless deposition in HF solutions $[19,20]$. In particular, the electroless process is relatively simple, of low cost since it does not require special equipment and it can be performed at classical chemical laboratories at room conditions. However, the effect of the etching solution composition and their relation to the properties of Si substrate (e.g. conductivity) is not well understood. In many investigations, Si nanostructures have been fabricated by MACE using Ag as a catalyst. However, the deposition of Ag particles on highly doped Si substrates in the most cases has been carried out with vacuum techniques such as sputtering or thermal evaporation [21, 22], since in the case of the electroless deposition, the process time should be adjusted according to the doping concentration to achieve a uniform film of particles [23]. On the other hand, the concentration of the Ag precursor solution should also be optimized [24].

For the MACE process, the concentrations of $\mathrm{HF}$ and $\mathrm{H}_{2} \mathrm{O}_{2}$ must be modified depending on the resistivity of the Si substrate, to produce Si nanostructures [25, 26]. In particular, a highly doped $\mathrm{Si}$ is more complicated to etch, since a high porosification level of Si occurs all over the Si sample regardless of the position of the catalyst particles [27]. This occurs due to the high availability of electronic holes (from the etching solution or from Si substrate), which are necessary for the etching process. The etching profiles and rates are determined by two competing processes: etching catalyzed by the metal particles, and porosification caused by the high availability of electronic holes in highly doped $\mathrm{Si}$. There are a limited number of papers reporting on the production of Si structures by MACE using highly doped substrates. Additionally, this "high doping" is limited to resistivities of $0.003 \Omega \cdot \mathrm{cm}$ or higher [28, 29]. Particularly, Si nanowalls produced by MACE without the need of photolithography are relatively scarce, and they have been produced mainly using substrates of resistivities higher than $1 \Omega \cdot \mathrm{cm}[30,31]$.

To the knowledge of the authors, there are no works on MACE explaining the mechanism of chemical deposition of $\mathrm{Ag}$ as a function of the doping level, neither how it affects the etching process. Shimizu et al. [19] reported the formation of Si structures with morphologies "nanowire", "porous wall" and "polished" out of p-type (100) Si substrates with resistivities of 1000, 10 and $0.01 \Omega \cdot \mathrm{cm}$. They used a single-step MACE using Ag metal as the catalyst. They concluded that regardless of the resistivity of $\mathrm{Si}$ substrate, by increasing the $\mathrm{AgNO}_{3}$ concentration in the etching solution, the surface morphology of etched Si changes from nanowire to porous wall, and finally, polished. Yousong et al. [26] used Si wafers (100) (with not detailed resistivity) to fabricate Si nanowires by MACE using Ag as catalyst. They stated that by controlling the $\mathrm{H}_{2} \mathrm{O}_{2}$ concentration in the etching solution, SiNWs can be obtained. Zhang et al. [32] fabricated nanowires arrays on p-type Si substrates with both (100) and (111) orientation and different resistivity: $7-13 \Omega \cdot \mathrm{cm}$ and 0.003-0.005 $\Omega \cdot \mathrm{cm}$, by the 2 step MACE method using Ag nanoparticles as catalyst. In the second step they used a room-temperature aqueous solution of hydrofluoric acid and hydrogen peroxide. For every kind of silicon wafer, the effect of etching conditions, such as components of etchant, temperature and time, were systematically investigated. They found that the silicon nanowires 
arrays possess the same type and same doping level of the starting wafer and that Si substrates with both orientations presented the (100) crystallographic direction. However, the effect of the Ag particles deposition on Si substrates with different resistivity was not considered.

This work deals with the production of Si nanowalls by MACE, using Si wafers in a wide range of resistivities: $15-25 \Omega \cdot \mathrm{cm}, 0.01-0.02 \Omega \cdot \mathrm{cm}$ and $0.0005-0.0007 \Omega \cdot \mathrm{cm}$. This is the first time that nanowalls are obtained out of substrates of resistivity smaller than $0.001 \Omega \cdot \mathrm{cm}$. The mechanisms of chemical deposition of $\mathrm{Ag}$ particles and MACE using the different substrates are explained. Special attention is paid at the effect of the doping concentration. A correlation between doping level, Ag deposition and MACE is presented here.

\section{Experimental}

The procedure to produce Si nanowalls consists of two steps: first, a deposition of dendritic silver particles (a), leaving elongated interstices in between, then the second, the MACE process (b), optimizing the etching solutions for each resistivity of Si used. Fig. 1 shows a schematic illustration of the deposition of the particles (a), and of the further etching process (b). As it can be observed, the interstices between $\mathrm{Ag}$ particles become the Si nanowalls after the etching process. Around the positions of the particles are located, trenches are produced.
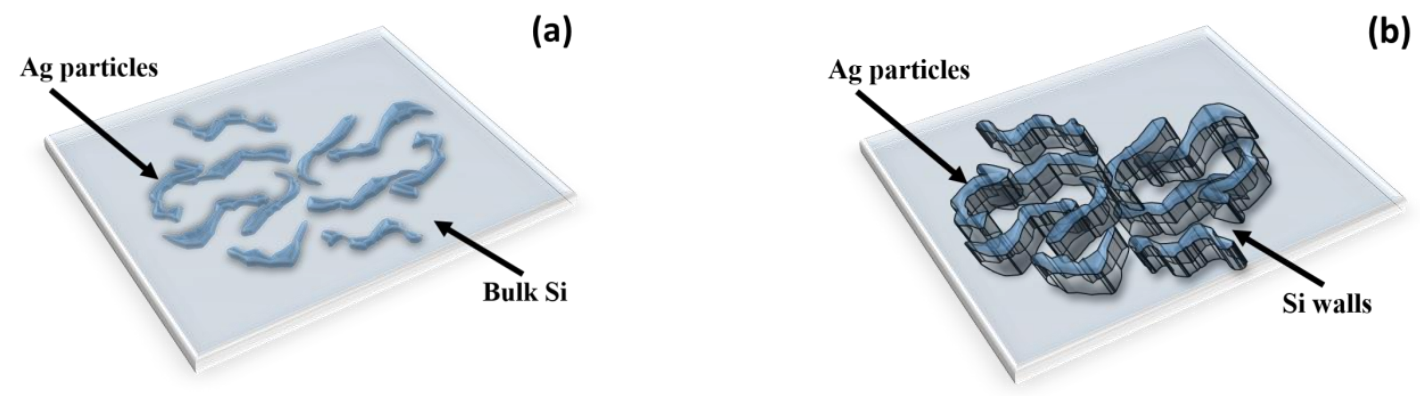

Fig. 1. Schematic illustration of the processes to fabricate Si nanowalls: (a) deposition of Ag dendritic particles leaving elongated interstices; (b) MACE process leading to formation of trenches located at the sites of particles, leaving nanowalls in between.

Single side polished p-type (boron doped) (100) Si wafers with resistivities of $15-25 \Omega \cdot \mathrm{cm}, 0.01$ $0.02 \Omega \cdot \mathrm{cm}$ and $0.0005-0.0007 \Omega \cdot \mathrm{cm}$, were used for the experiments. Prior to the production of nanowalls, the Si substrates were cleaned with ethanol ( $\geq 99.8 \%$ purity, Sigma-Aldrich) and acetone ( $\geq 99.9 \%$ purity, Sigma-Aldrich) for $10 \mathrm{~min}$ in ultrasonic bath, and they were rinsed with ultra-pure (UP) water of $18.2 \mathrm{M} \Omega \cdot \mathrm{cm}$ afterwards. Then, the samples were immersed in a solution of HF (48\%, EMSURE) $10 \%$ v/v for $5 \mathrm{~min}$, and they were rinsed with UP water afterwards.

After the cleaning procedure, Ag particles were deposited by an electroless process by immersion of the $\mathrm{Si}$ substrates in an aqueous solution composed of $0.01 \mathrm{M}$ of $\mathrm{AgNO}_{3}$ and $\mathrm{HF}$ (48\%), in a volumetric proportion 25:0.5, for $30 \mathrm{~s}$ at $30{ }^{\circ} \mathrm{C}$. The $\mathrm{Si}$ substrates were rinsed with UP water afterwards. The etching solution consisted of $\mathrm{HF}, \mathrm{H}_{2} \mathrm{O}_{2}$ and $\mathrm{H}_{2} \mathrm{O}$. The starting composition was 
4:4:32 v/v/v. The composition of the etchant was optimized to be able to obtain nanowalls out of $\mathrm{Si}$ with different resistivities. The etching temperature was $30^{\circ} \mathrm{C}$, and the time was set to $30 \mathrm{~min}$ for all samples. After carrying out the MACE process, the samples were rinsed with UP water. All the samples were analyzed using a Zeiss Ultra55 microscope with high-resolution Schottky thermal field emission gun (Schottky SEM-FEG).

\section{Results and discussion}

\subsection{Chemical deposition of Ag nanoparticles}

The reaction mechanism of the deposition of $\mathrm{Ag}$ particles using $\mathrm{AgNO}_{3}, \mathrm{Si}$ and $\mathrm{HF}$ as precursors, can be described by the following equations (1) and (2) [5]:

$6 \mathrm{HF}+\mathrm{Si} \rightarrow \mathrm{H}_{2} \mathrm{SiF}_{6}+4 \mathrm{e}^{-}+4 \mathrm{H}^{+}$

$\mathrm{Ag}^{+}+\mathrm{e}^{-} \rightarrow \mathrm{Ag}^{0}$

$\mathrm{HF}$ etches $\mathrm{Si}$ (slow reaction) and produces electrons that are caught up by $\mathrm{Ag}^{+}$ions, which are transformed to Ag metallic particles.

However, it is known that the dissolution of Si proceeds faster with the availability of electronic holes according to reaction (3) [33]:

$6 \mathrm{HF}+\mathrm{Si}+4 \mathrm{~h}^{+} \rightarrow \mathrm{H}_{2} \mathrm{SiF}_{6}+4 \mathrm{H}^{+}$

Nevertheless, if there is a high availability of electronic holes in the substrate (e.g. when Si p-type is highly doped), the production of electrons, necessary for the electroless deposition of $\mathrm{Ag}$, is limited. The overall dissolution can be understood as a combination of (1) and (3):

$6 \mathrm{HF}+\mathrm{Si}+\mathrm{xh}^{+} \rightarrow \mathrm{H}_{2} \mathrm{SiF}_{6}+\mathrm{ye}^{-}+4 \mathrm{H}^{+}$

where $\mathrm{x}+\mathrm{y}=4$.

If there is a high availability of electronic holes, the production of electrons tends to zero.

Fig. 2 shows SEM micrographs of the Ag particles deposited by the electroless method on p-type $\mathrm{Si}$ substrates of three resistivities. In all the samples the Ag particles coalesce, as needed for the production of nanowalls by MACE. Nevertheless, there are big differences in the size and spatial distribution of the Ag particles from sample to sample. Fig. 2a shows the Ag particles deposited on substrates of $0.0005-0.0007 \Omega \mathrm{cm}$. The average size of the agglomerated particles is $213 \mathrm{~nm}$. In (b) one can see a micrograph of the Ag particles deposited on substrates of 0.01-0.02 $\Omega \mathrm{cm}$. They have an average size of $68 \mathrm{~nm}$. A micrograph of the Ag particles deposited on substrates of 15-25 $\Omega \mathrm{cm}$ is shown in (c). The particles have an average size of $87 \mathrm{~nm}$. 

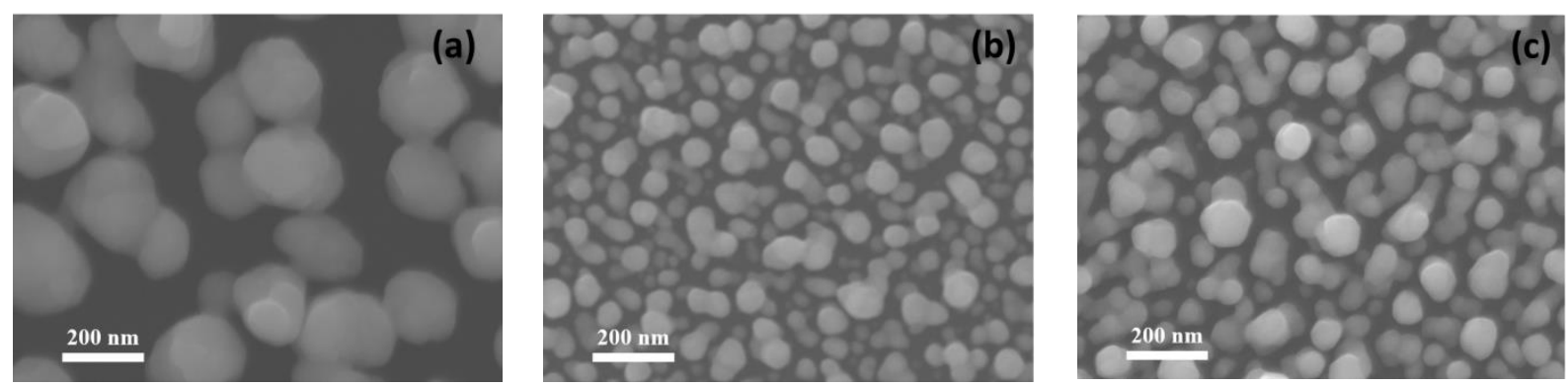

Fig. 2. SEM micrographs of Ag particles deposited by electroless on p-type Si substrates with resistivity a) $0.0005-0.0007 \Omega \cdot \mathrm{cm}$, (b) $0.01-0.02 \Omega \cdot \mathrm{cm}$, and (c) $15-25 \Omega \cdot \mathrm{cm}$ using $0.01 \mathrm{M}$ fresh solution of $\mathrm{AgNO}_{3}$ and $\mathrm{HF}$ for $30 \mathrm{~s}$.

The spatial distribution is similar for the samples of $15-25$ (c) and $0.01-0.02 \Omega \cdot \mathrm{cm}$ (b), but the separation between particles of the sample of $0.0005-0.0007 \Omega \cdot \mathrm{cm}$ (a) is much larger (about 300 $\mathrm{nm}$ in contrast to $70 \mathrm{~nm}$ for the other samples). The thermodynamics and kinetics involved in the deposition of metals on semiconductors are complicated due to energetic interactions between the two materials causing either energy barriers or accumulation regions. Despite this, one can understand the deposition process of the samples of this work supported on the schematic illustration of Fig. 3.

Fig. 3a explains schematically how is the deposition mechanism for the sample with resistivity 0.0005-0.0007 $\Omega \cdot \mathrm{cm}$. Particularly in this sample, the production of electrons for the reduction of $\mathrm{Ag}^{+}$is limited, because of the abundance of electronic holes, as indicated in equation (4). However, once the first Ag particles nucleate, they attract the electrons through an electric field of a space charge region (SCR) formed under the particles [34]. The SCR is thin with strong field, because of the high doping density. Then, an over deposition of Ag on the first nucleated Ag particles has a much higher probability than a nucleation of new particles. This is why the distance between particles is large. Even though, the particles could start coalescing with the time (see Fig. 2a).
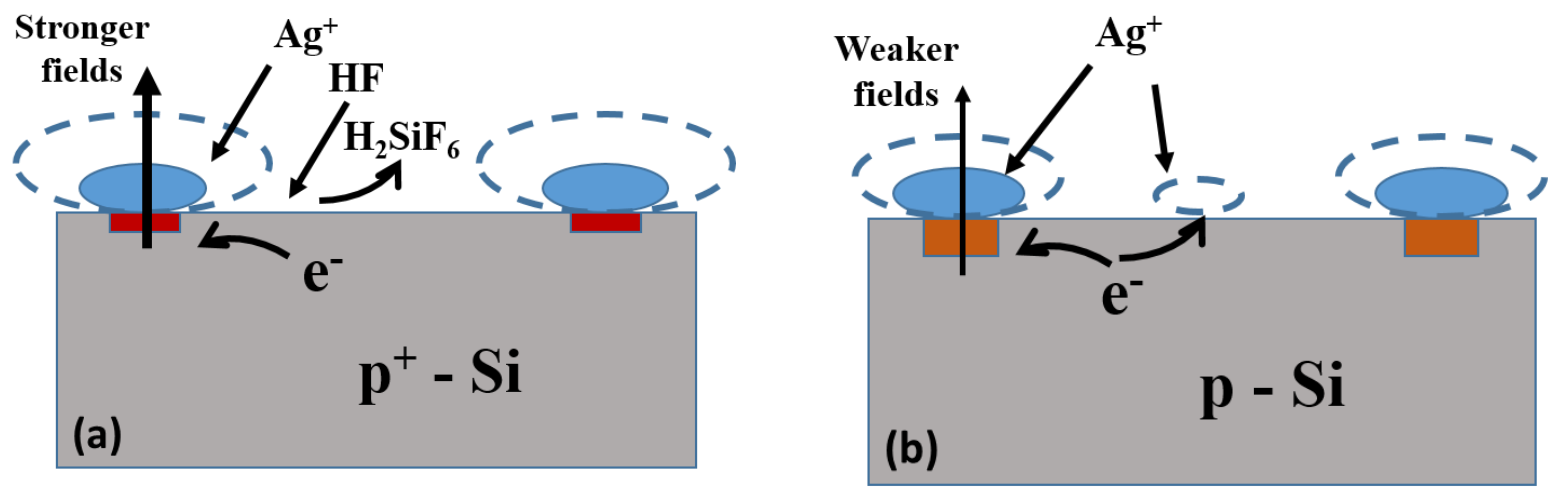

Fig. 3. Schematic illustration of the deposition mechanism of Ag particles: (a) for the sample of 0.0005$0.0007 \Omega \cdot \mathrm{cm}$; (b) for the samples of $15-25$ and $0.01-0.02 \Omega \cdot \mathrm{cm}$. The dotted lines indicate the sizes of the Ag particles (filled ovals) at longer deposition times. 
In the case of the samples with resistivities of $15-25$ and $0.01-0.02 \Omega \cdot \mathrm{cm}$, the deposition process (presented in Fig. 3b) is similar. Below the deposited particles, an SCR is formed with a similar shape as for the sample with low resistivity. However, it is wider and its field is lower. On the other hand, there is a higher availability of electrons for the deposition, given by the lower doping of Si wafer. Due to these conditions, after nucleating the first Ag particles, there is a similar probability to deposit on the exiting Ag particles than nucleating new particles. Thus, as observed in Fig. 2b and Fig. 2c, the distances between particles are smaller, and there is a larger distribution of sizes. The only difference that can be found when comparing the sample of $15-25 \Omega \cdot \mathrm{cm}$ with the one of 0.01-0.02 $\Omega \cdot \mathrm{cm}$, is that the particles for the former are larger (the deposition rate is faster at this resistivity). The reason is the higher availability of electrons for the reduction of $\mathrm{Ag}^{+}$, as indicated by equation (4). It is important to mention that in the three cases the particles agglomerate to form dendrites leaving interstices, as needed for the production of nanowalls by MACE.

\subsection{Fabrication of Si nanowalls by MACE}

\subsubsection{Nanowalls from Si wafers of $15-25 \Omega \cdot \mathrm{cm}$}

At first, the MACE process (with Ag catalyst) involves the formation of electronic holes at the sites of the catalyst particles. The chemical equation describing this process is as follows [35]:

$\mathrm{H}_{2} \mathrm{O}_{2}+2 \mathrm{H}^{+} \stackrel{A g}{\rightarrow} 2 \mathrm{H}_{2} \mathrm{O}+2 \mathrm{~h}^{+}$

The electronic holes speed up the dissolution of $\mathrm{Si}$ in the presence of $\mathrm{HF}$. The overall dissolution reaction can be described by equation (4). According to this reaction, $\mathrm{H}^{+}$ions can be reduced and lead to $\mathrm{H}_{2}$ evolution, which can be described by equation (6) [35]:

$6 \mathrm{HF}+\mathrm{Si}+\mathrm{nh}^{+} \rightarrow \mathrm{H}_{2} \mathrm{SiF}_{6}+\mathrm{nH}^{+}+(2-\mathrm{n} / 2) \mathrm{H}_{2}$

where $n$ depends strongly on the proportion of $\mathrm{HF}$ to $\mathrm{H}_{2} \mathrm{O}_{2}$ (etching to oxidation rate). It is important to mention that the etching rate and the evolution of $\mathrm{H}_{2}$ depend on the availability of electronic holes in the Si substrate, which is given by the doping level. More details on these dependencies will be discussed below.

Fig. 4 shows SEM micrographs of the Si sample with resistivity of $15-25 \Omega \cdot \mathrm{cm}$, etched in the solution of HF: $\mathrm{H}_{2} \mathrm{O}_{2}: \mathrm{H}_{2} \mathrm{O}$ 4:4:32 v/v/v. The micrograph of (a) presents the surface morphology of the etched sample, where black circular regions denote pores. The micrograph (b) is a cross sectional view, where vertical pores are evident. The depth of the pores is of $39 \pm 1.5 \mu \mathrm{m}$, indicating an etching rate of $1.3 \mu \mathrm{m} / \mathrm{min}$. The etching rate is good compared with another work where a value of $30 \mu \mathrm{m} / \mathrm{h}$ has been reported for the production of SiNWs out of a Si wafer with resistivity of 15-25 $\Omega \cdot \mathrm{cm}$ [5]. However, the morphology of the pores is not the appropriate to form nanowalls. Isolated pores are obtained instead of coalesced pores, in contrast to what was expected when looking at the morphology of the merged $\mathrm{Ag}$ particles used for etching. $\mathrm{H}_{2}$ bubbles generated during the etching of Si may evolve from around the Ag particles, considering that there is an 
excess of $\mathrm{H}_{2} \mathrm{O}_{2}$ that caused an additional porosification (and additional reaction mechanisms), not just at the pore tips. The bubbling during the etching process could lead to splitting the Ag particles and their aggregates. To support this theory, the amount of $\mathrm{H}_{2} \mathrm{O}_{2}$ was increased.

Fig. 5 shows SEM micrographs of a Si 15-25 $\Omega \cdot \mathrm{cm}$ sample etched in a solution of $\mathrm{HF}: \mathrm{H}_{2} \mathrm{O}_{2}: \mathrm{H}_{2} \mathrm{O}$ $2: 4: 34 \mathrm{v} / \mathrm{v} / \mathrm{v}$. (a) shows well isolated pores, even more isolated than when using the previous composition of the etchant $\left(\mathrm{HF}: \mathrm{H}_{2} \mathrm{O}_{2}: \mathrm{H}_{2} \mathrm{O} 4: 4: 32 \mathrm{v} / \mathrm{v} / \mathrm{v}\right)$. This confirms the theory of Ag particle dissociation, most probably due to the bubbling. This bubbling has been used in other works even for controlling the shape of the produced structures [35]. The cross section image (Fig. 5 (b)) shows pores with conical shape. This shape is common when an excess of $\mathrm{H}_{2} \mathrm{O}_{2}$ is used [36]. The average depth of the pores is $4.0 \pm 0.2 \mu \mathrm{m}$, indicating an etching rate of $0.12 \mu \mathrm{m} / \mathrm{min}$.
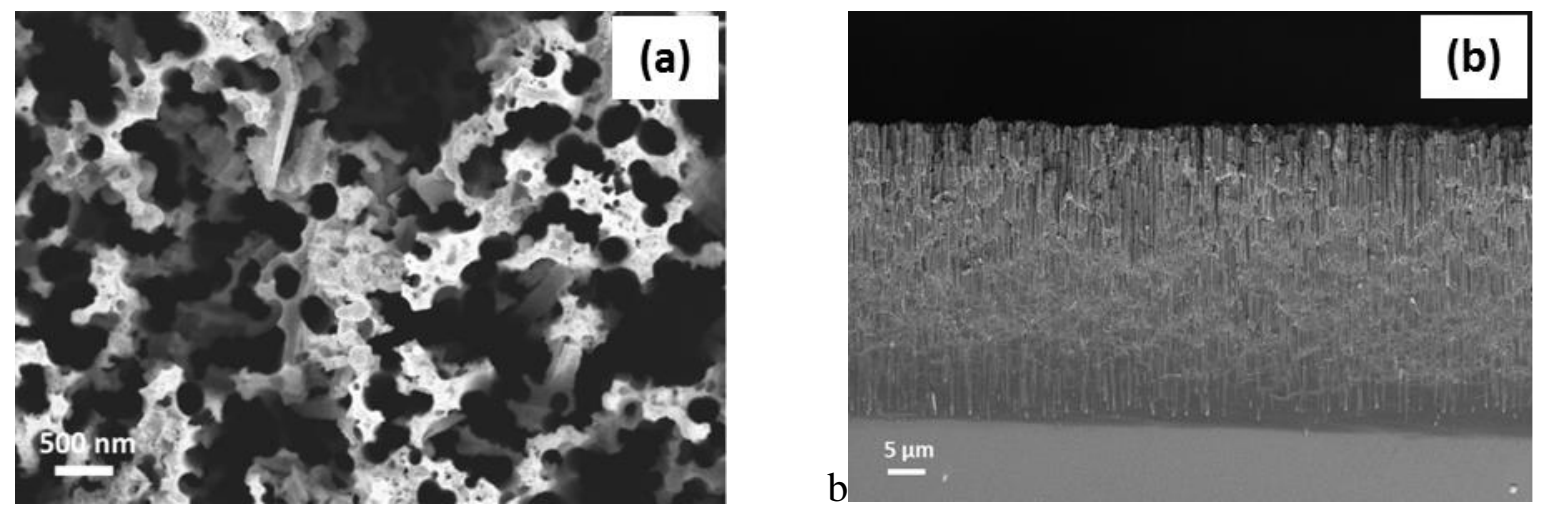

Fig. 4. SEM images of $\mathrm{Si}$ wafer with resistivity of $15-25 \Omega \cdot \mathrm{cm}$ etched in a solution of HF: $\mathrm{H}_{2} \mathrm{O}_{2}: \mathrm{H}_{2} \mathrm{O}$ 4:4:32 v/v/v: (a) surface morphology and (b) cross section view.
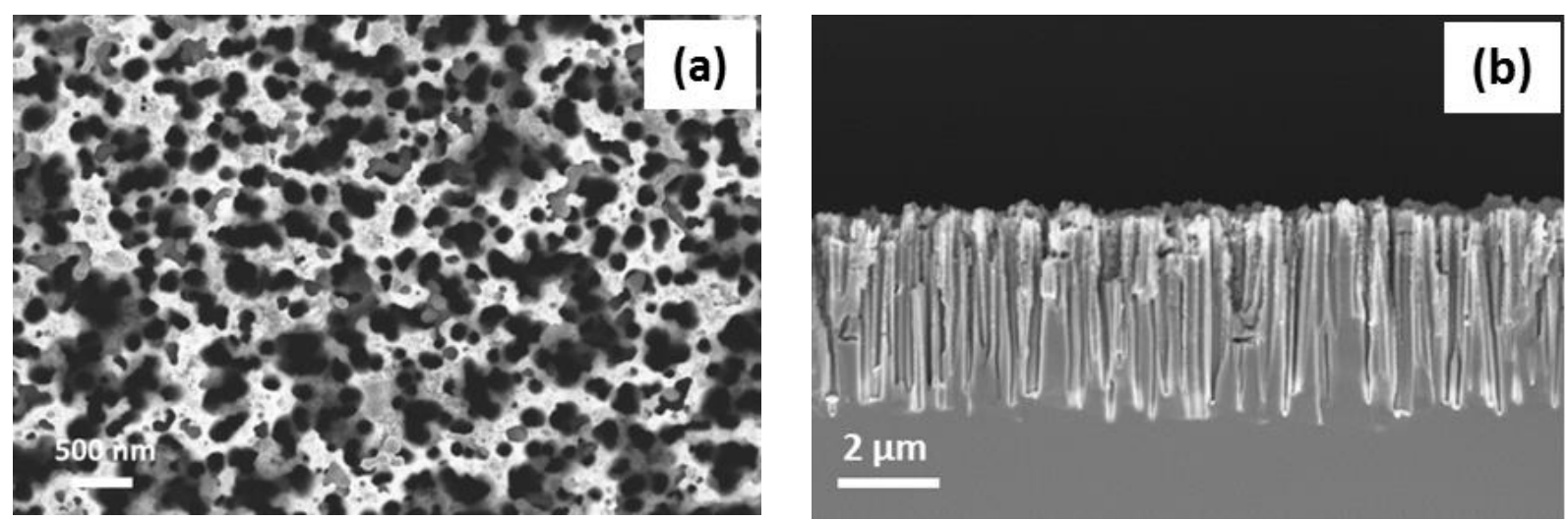

Fig. 5. SEM images of $\mathrm{Si}$ wafer with resistivity of $15-25 \Omega \cdot \mathrm{cm}$ etched in a solution of $\mathrm{HF}: \mathrm{H}_{2} \mathrm{O}_{2}: \mathrm{H}_{2} \mathrm{O}$ 2:4:34 v/v/v: (a) surface morphology and (b) cross section view.

Fig. 6 shows SEM micrographs of Si 15-25 $\Omega \cdot \mathrm{cm}$ sample etched in an optimized etching solution $\left(\mathrm{HF}: \mathrm{H}_{2} \mathrm{O}_{2}: \mathrm{H}_{2} \mathrm{O}, 4: 1: 35 \mathrm{v} / \mathrm{v} / \mathrm{v}\right)$ to obtain $\mathrm{Si}$ nanowalls. In the way to reach the optimized etchant some other tests were performed varying the amount of either $\mathrm{HF}$ or $\mathrm{H}_{2} \mathrm{O}_{2}$ (Table $\mathrm{S} 1$ of supplementary information). This solution was selected as the optimal etchant to prepare nanowalls with the lowest porosity. Fig. 6 (a) shows a micrograph of the surface with the optimized morphology which consists of nanowalls surrounded by trenches (seen as black regions). Fig. 6 
(b) shows the nanowalls in cross section. The height of the nanowalls is $11.0 \pm 0.7 \mu \mathrm{m}$, thus the etching rate is $0.37 \mu \mathrm{m} / \mathrm{min}$. The optimized etchant contained less $\mathrm{H}_{2} \mathrm{O}_{2}$ than the solutions used for the two previous samples, minimizing bubbling and porosification of the walls. This etching solution was used as a starting etchant for the experiments for Si substrates with resistivities of 0.01-0.02 and 0.0005-0.0007 $\Omega \cdot \mathrm{cm}$.
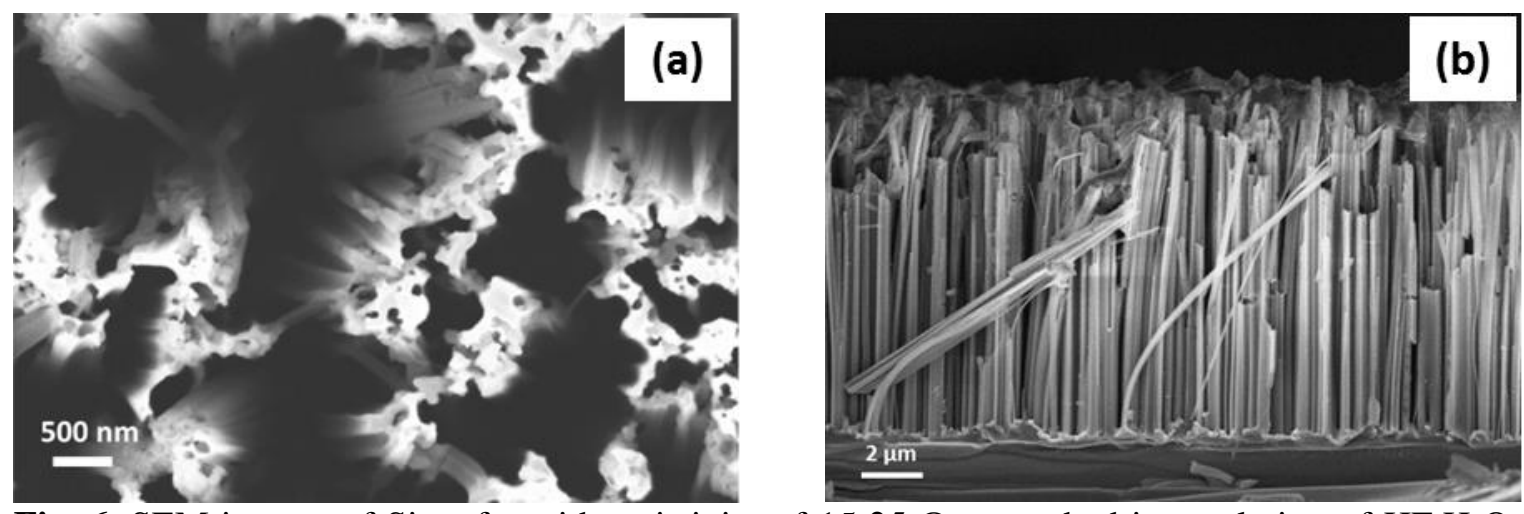

Fig. 6. SEM images of Si wafer with resistivity of $15-25 \Omega \cdot \mathrm{cm}$ etched in a solution of $\mathrm{HF}: \mathrm{H}_{2} \mathrm{O}_{2}: \mathrm{H}_{2} \mathrm{O}$ 4:1:35 v/v/v: (a) surface morphology and (b) cross section view.

\subsubsection{Nanowalls from Si wafers of $0.01-0.02 \Omega \cdot c m$}

SEM micrographs corresponding to $\mathrm{Si}$ substrates with resistivity $0.01-0.02 \Omega \cdot \mathrm{cm}$ etched with a solution of $\mathrm{HF}: \mathrm{H}_{2} \mathrm{O}_{2}: \mathrm{H}_{2} \mathrm{O}$ 4:1:35 v/v/v (optimized to obtain nanowalls out of $\mathrm{Si}$ wafers with resistivity of $15-25 \Omega \cdot \mathrm{cm}$ ) are shown in Fig. 7. (a) shows the surface morphology, consisting of thick walls. During SEM analysis a charging effect was observed, indicating the insulating properties of the sample most probably due to the formation of pores in the walls. The cross section image (Fig. 7 (b)) shows the nanowalls with the height of $7.0 \pm 0.3 \mu \mathrm{m}$, which means that the etching rate was of $0.23 \mu \mathrm{m} / \mathrm{min}$. The problem with this sample is that the walls are very thick, with thickness not corresponding to the size of the interstices between Ag particles right after deposition. As observed for the Si samples of resistivity $15-25 \Omega \cdot \mathrm{cm}$, the $\mathrm{H}_{2}$ bubbles evolution during the etching process may lead to the particle displacement from their initial positions, and formation of agglomerates. The particles may tend to agglomerate due to the porosification of the walls. 

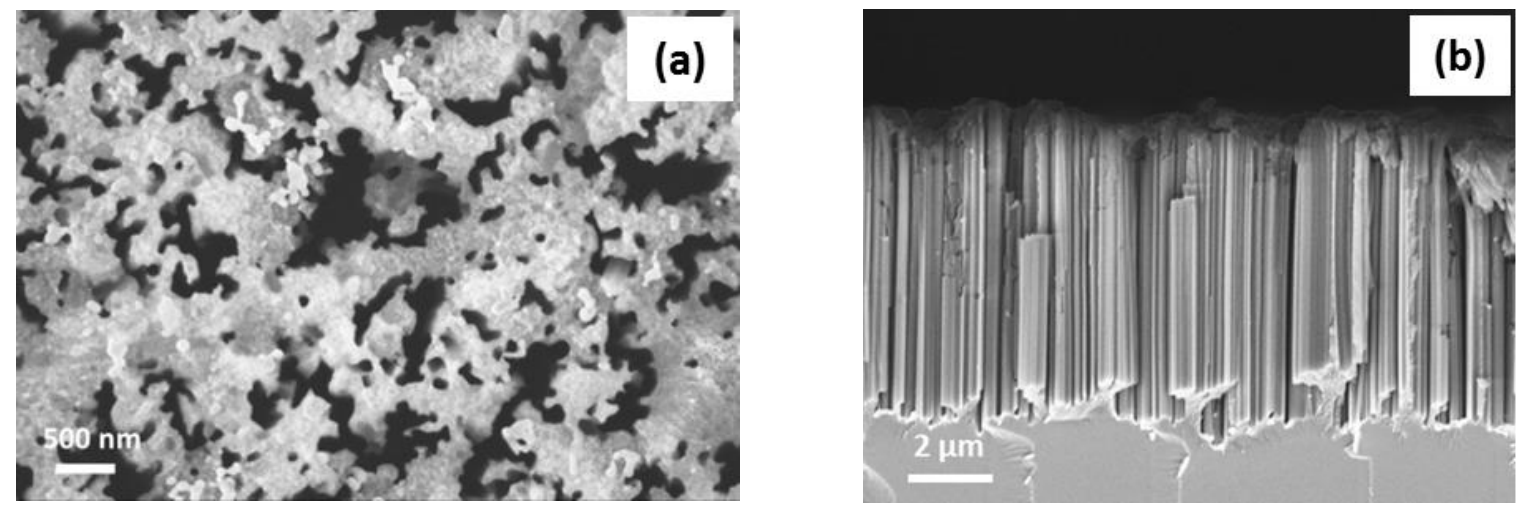

Fig. 7. SEM images of Si wafer with resistivity of 0.01-0.02 $\Omega \cdot \mathrm{cm}$ etched in a solution of $\mathrm{HF}: \mathrm{H}_{2} \mathrm{O}_{2}: \mathrm{H}_{2} \mathrm{O}$ $4: 1: 35 \mathrm{v} / \mathrm{v} / \mathrm{v}$ : (a) surface morphology and (b) cross section view.

To minimize the bubbling problem and the porosification of the walls, the amount of $\mathrm{H}_{2} \mathrm{O}_{2}$ was greatly reduced. The optimized solution was $\mathrm{HF}: \mathrm{H}_{2} \mathrm{O}_{2}: \mathrm{H}_{2} \mathrm{O} 4: 0.2: 35.8 \mathrm{v} / \mathrm{v} / \mathrm{v}$. Some other tests were performed varying one at a time the amount of both $\mathrm{HF}$ and $\mathrm{H}_{2} \mathrm{O}_{2}$ (Table $\mathrm{S} 2$ of supplementary information), and etching solution formed by $\mathrm{HF}: \mathrm{H}_{2} \mathrm{O}_{2}: \mathrm{H}_{2} \mathrm{O}$ 4:0.2:35.8 v/v/v was selected as optimal to prepare nanowalls with the lowest porosity. Fig. 8 shows SEM micrographs of the Si sample with resistivity of $0.01-0.02 \Omega \cdot \mathrm{cm}$ etched in the optimized solution. Fig. 8 (a) shows a top view, where nanowalls can be observed. The structures tend to collapse, probably due to their small thicknesses and their significant height of around $13.0 \pm 0.9 \mu \mathrm{m}$, as shown in a cross section image in Fig. 8 (b). The etching rate was of $0.47 \mu \mathrm{m} / \mathrm{min}$. Taking a look at the $\mathrm{HF}: \mathrm{H}_{2} \mathrm{O}_{2}$ ratio, it can be inferred that for etching samples of medium resistivity, the concentration of $\mathrm{HF}$ in the etchant must be dominant.
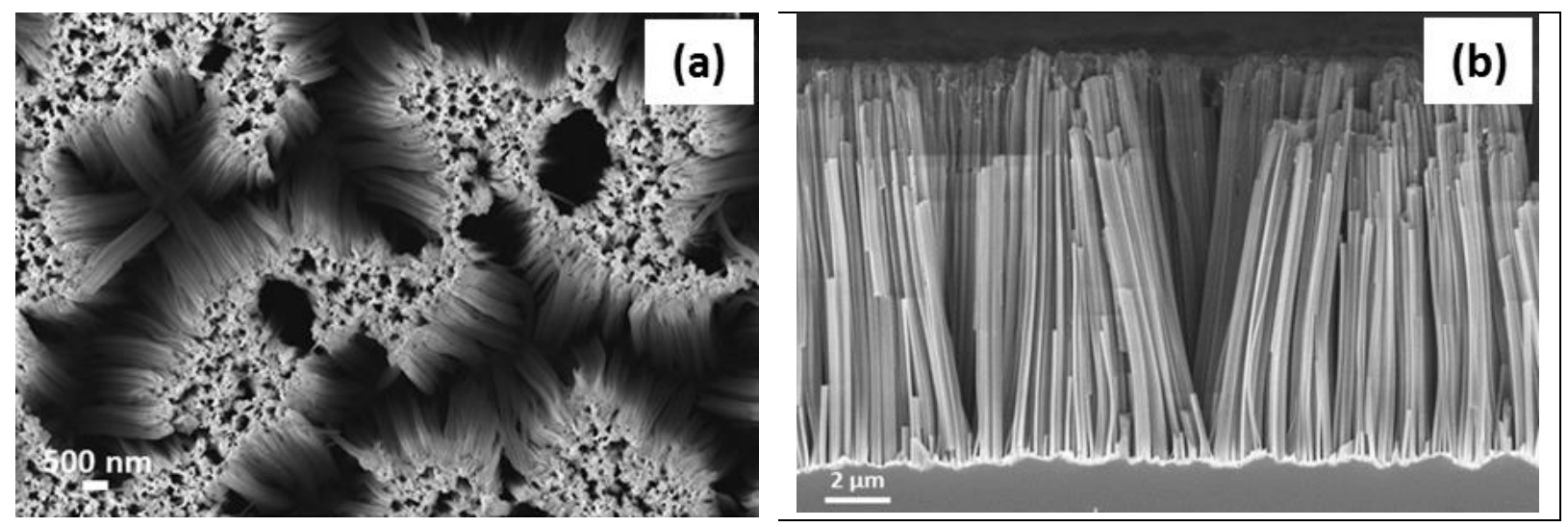

Fig. 8. SEM images of $\mathrm{Si}$ wafer with resistivity of $0.01-0.02 \Omega \cdot \mathrm{cm}$ etched in a solution of HF: $\mathrm{H}_{2} \mathrm{O}_{2}: \mathrm{H}_{2} \mathrm{O}$ 4:0.2:35.8 v/v/v: (a) surface morphology and (b) cross section view.

\subsubsection{Nanowalls from Si wafers of $0.0005-0.0007 \Omega \cdot \mathrm{cm}$}

Fig. 9 shows a SEM micrograph of Si 0.0005-0.0007 $\Omega \cdot \mathrm{cm}$ etched in a solution of $\mathrm{HF}: \mathrm{H}_{2} \mathrm{O}_{2}: \mathrm{H}_{2} \mathrm{O}$ $4: 1: 35 \mathrm{v} / \mathrm{v} / \mathrm{v}$ (the optimized etchant to obtain nanowalls out of Si wafers with resistivity of 15-25 
$\Omega \cdot \mathrm{cm}$ ). Some Ag agglomerates can be observed on the surface but no structures characteristic of etched Si. The inset at 250,000X shows some surface modifications indicating a negligible etching, most probable due to the high surface porosification originating from the availability of electronic holes. The etching seems to occur everywhere and not only at the sites of Ag particles, because of the high availability of electronic holes. The porosification should have been so dense, that HF has dissolved the porous $\mathrm{Si}$.

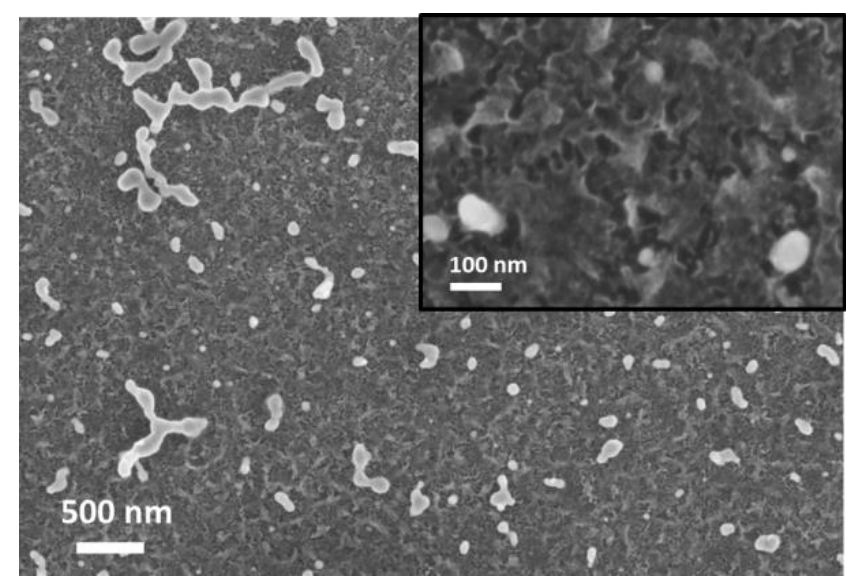

Fig. 9. SEM micrograph of the Si surface of a sample with resistivity of $0.0005-0.0007 \Omega \cdot \mathrm{cm}$ etched in a solution $\mathrm{HF}: \mathrm{H}_{2} \mathrm{O}_{2}: \mathrm{H}_{2} \mathrm{O} 4: 1: 35 \mathrm{v} / \mathrm{v} / \mathrm{v}$. The inset is a magnification at 250,000X.

The etching solution was optimized to obtain nanowalls. Before, several tests were carried out, using different compositions of the etchant (see Table $\mathrm{S} 3$ of the supplementary information), until an optimal solution was found: $\mathrm{HF}: \mathrm{H}_{2} \mathrm{O}_{2}: \mathrm{H}_{2} \mathrm{O}$ 20:0.2:19.8 v/v/v. The SEM micrograph presented in Fig. 10 (a) shows a dendritic surface morphology of white sections (Si nanowalls) surrounded by dark regions (trenches). Fig. 10 (b) shows a cross section view of the same sample, indicating the formation of nanowalls with a height of $3.0 \pm 0.1 \mu \mathrm{m}$ and the etching rate $0.10 \mu \mathrm{m} / \mathrm{min}$. Comparing the composition of the etchant used for this sample with the one for the sample of 0.01$0.02 \Omega \cdot \mathrm{cm}$, it is evident that much more HF was needed. The small amount of $\mathrm{H}_{2} \mathrm{O}_{2}$ is necessary to form a small gradient of electronic holes at the sites of presence of Ag particles. An excess of $\mathrm{HF}$ is needed to etch away without limitation of the etching rate. Due to the larger availability of electronic holes at the pore tips, the etching rate is higher at these sites and Si nanowalls can be formed. However, the walls are short, and may be porous. The presence of pores can be deduced from the charging effect observed during the SEM measurements. 

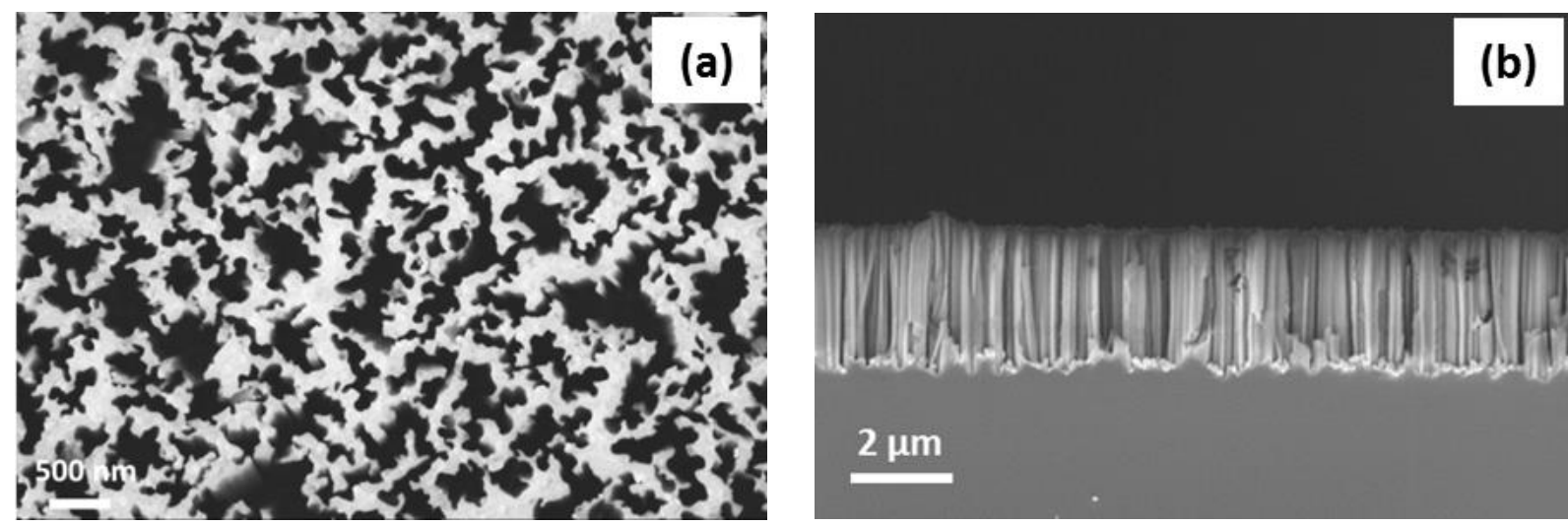

Fig. 10. SEM images of $\mathrm{Si}$ with resistivity of $0.0005-0.0007 \Omega \cdot \mathrm{cm}$ etched in a solution HF: $\mathrm{H}_{2} \mathrm{O}_{2}: \mathrm{H}_{2} \mathrm{O}$ 20:0.2:19.8 v/v/v: (a) surface morphology and (b) cross section view.

Table 1 shows a summary of the optimized compositions of the etchants. It can be seen that for MACE, to move from a high to a medium resistivity, it is necessary to reduce the amount of oxidant $\left(\mathrm{H}_{2} \mathrm{O}_{2}\right)$. This is mandatory due to the high availability of electronic holes in the semiconductor. It is just important to create a small difference in the concentration of holes, to inject them right under the catalyst (Ag) particles to increase the etching probability at those positions. For the sample of the lowest resistivity, in addition, it is necessary to increase the amount of HF (so that the etching reaction rate is not the limiting factor).

Table 1. Summary of the optimal etching solutions used to produce nanowalls out of Si with the three resistivities studied in this work.

\begin{tabular}{|c|c|c|c|c|c|}
\hline & \multicolumn{3}{|c|}{ Volume proportion } & \multirow[b]{2}{*}{$\begin{array}{c}\text { Height } \\
(\mu \mathrm{m})\end{array}$} & \multirow[b]{2}{*}{$\begin{array}{l}\text { Etching rate } \\
(\mu \mathrm{m} / \mathrm{min})\end{array}$} \\
\hline $\begin{array}{c}\text { Si Resistivity } \\
(\Omega \cdot \mathrm{cm})\end{array}$ & HF & $\mathrm{H}_{2} \mathrm{O}_{2}$ & $\mathrm{H}_{2} \mathrm{O}$ & & \\
\hline $15-25$ & 4 & 1 & 35 & $11.0 \pm 0.7$ & $0.3-0.4$ \\
\hline 0.01-0.02 & 4 & 0.2 & 35.8 & $13.0 \pm 0.9$ & $0.4-0.5$ \\
\hline $0.0005-0.0007$ & 20 & 0.2 & 19.8 & $3.0 \pm 0.1$ & $0.08-0.10$ \\
\hline
\end{tabular}

\section{Conclusions}

Dendritic growth of Ag particles has been accomplished chemically, on Si substrates of high, medium and low resistivities. The growth depends of the electric field of the space charge region form below the first nucleated particles, which is dependent of the doping level. For low resistivity $\mathrm{Si}$ samples, the electric field is much higher than for medium and high resistivity $\mathrm{Si}$, generating bigger Ag particles with a large separation between them, while in the other ones, the distances among particles are smaller.

For the first time nanowalls were obtained out of substrates of resistivity smaller than $0.001 \Omega \cdot \mathrm{cm}$. The resistivity of the Si substrates and concentrations of $\mathrm{HF}$ and $\mathrm{H}_{2} \mathrm{O}_{2}$ in etching solution affect 
the formation of nanowalls. For substrates with high resistivity $(15-25 \Omega \cdot \mathrm{cm})$, it was observed that a high concentration of $\mathrm{H}_{2} \mathrm{O}_{2}$ causes additional lateral porosification. This effect is more evident in samples with a high concentration of electronic holes (samples with low resistivities), so it is necessary to reduce considerably the $\mathrm{H}_{2} \mathrm{O}_{2}$ concentration. On the other hand, the optimization of etching solution allowed that the bubbling of $\mathrm{H}_{2}$ do not displace the dendritic Ag particles. Additionally, the HF had to be increased for the sample of lowest resistivity, so that the etching reaction rate is not the limiting factor. Considering all these factors, the etching process led to formation of nanowalls.

\section{Acknowledgements}

The authors acknowledge the support of BUAP with the project VIEP2019-100523072 and the support of CONACyT with the project CB-2014-01-243407 and through the Mexican Energy Storage Network. The author V. Aca-López thanks CONACyT for a graduate student's scholarship.

\section{References}

[1] K. Q. Peng and S. T. Lee, "Silicon nanowires for photovoltaic solar energy conversion," Adv. Mater., vol. 23, no. 2, pp. 198-215, 2011.

[2] Y. Cui, Q. Wei, H. Park and C. M. Lieber, "Nanowire Nanosensors for Highly Sensitive and Selective Detection of Biological and Chemical Species," Science, vol. 293, no. 5533, pp. 1289-1292, 2001.

[3] E. Quiroga-González, E. Ossei-Wusu, J. Carstensen and H. Föll, "How to Make Optimized Arrays of Si Wires Suitable as Superior Anode for Li-Ion Batteries," J. Electrochem. Soc, vol. 158, no. 11, pp. E119-E123, 2011.

[4] T. E. Bell, P. T. Gennssen, D. DeMunter and M. Kuhl, "Porous silicon as a sacrificial material," $J$. Micromech. Microeng., vol. 6, p. 361, 1996.

[5] O. Pérez-Díaz, E. Quiroga-González and N. R. Silva-González, "Silicon microstructures through the production of silicon anowires by metal-assisted chemical etching used as sacrificial material," $J$. Mater Sci, vol. 54, pp. 2351-2357, 2019.

[6] Y. K. Choi, J. Zha, J. Grunes, J. Bokor and G. A. Somorjai, "Fabricaction of Sub-10-nm Silicon Nanowire Arrays by Size Reduction Lithography," J. Phys. Chem. B, vol. 107, pp. 3340-3343, 2003.

[7] K. M. Chang, K. S. You, J. H. Lin and J. T. Sheu, "An Alternative Process for Silicon Nanowire Fabrication with SLP and Wet Etching System," J. Electrochem. Soc., vol. 151, pp. G679-G682, 2004.

[8] R. Juhasz, N. Elfstrom and J. Linnros, "Controlled Fabrication of Silicon Nanowires by Electron Beam Lithography and Electrochemical Size Reduction," Nano Lett., vol. 5, no. 2, pp. 275-280, 2005. 
[9] H. I. Liu, D. K. Biegelsen, F. A. Ponce, N. M. Johson and R. F. Pease, "Selflimiting oxidation for fabricating sub5 nm silicon nanowires," Appl. Phys. Lett, vol. 64, p. 1383, 1994.

[10] J. Westwater, D. P. Gosain, S. Tomiya, S. Usui and H. Ruds, "Growth of silicon nanowires via gold/silane vapor-liquid-solid reaction," J.Vac. Sci. Technol. B, vol. 15, no. 3, pp. 554-557, 1997.

[11] Y. J. Zhang, Q. Zhang, Y. J. Wang, H. H. Zhou and J. Zhu, "Synthesis of thin Si whiskers (nanowires) using SiCl4," J. Cryst. Growth, vol. 226, no. 2-3, pp. 185-191, 2001.

[12] D. Gao, R. He, C. Carraro, R. T. Howe, P. Yang and R. Maboudain, "Selective Growth of Si Nanowire Arrays via Galvanic Displacement Processes in Water-in-Oil Microemulsions," J. Am. Chem. Soc., vol. 127, no. 13, pp. 4574-4575, 2005.

[13] Y. H. Zhang, X. J. Li, L. Zheng and Q. W. Chen, "Nondegrading Photoluminescence in Porous Silicon," Phys. Rev. Lett, vol. 81, no. 8, pp. 1710-1713, 1998.

[14] K. Q. Peng, J. J. Hu, Y. J. Yan, Y. Wu, H. Fang, Y. Xu, S. T. Lee and J. Zhu, "Fabrication of SingleCrystalline Silicon Nanowires by Scratching a Silicon Surface with Catalytic Metal Particles," Adv. Funct. Mater, vol. 16, no. 3, pp. 387-394, 2006.

[15] K. Q. Peng, H. Fang, J. Hu, Y. Wu, J. Zhu, Y. Yan and S. T. Lee, "Metal-Particle-Indiced, Highly Localized Site-Specific Etching of Si and Formation of Single-Crystalline Si Nanowires in Aqueous Fluoride Solution," Chem. Eur. J., vol. 12, no. 30, pp. 7942-7947, 2006.

[16] F. Bai, M. Li, R. Huang, D. Song, B. Jiang and Y. Li, "Template-free fabrication of silicon micropillar/nanowire composite structure by one-step etching," Nanoscale Research Letters, vol. 7, no. 1, pp. 557-561, 2012.

[17] A. Backes, M. Leitgeb, A. Bittner and U. Schmid, "Temperature Dependent Pore Formation in Metal Assisted Chemical Etching of Silicon," ECS J. of Solid State Sci. Technol., vol. 5, no. 12, pp. P653P656, 2016.

[18] Y. Harada, X. Li, P. W. Bohn and R. G. Nuzzo, "Catalytic Amplification of the Soft Lithographic Patterning of Si. Nanoelectrochemical Orthogonal Fotoluminescent Porous Si Pixel Arrays," J. Am. Chem. Soc., vol. 123, no. 36, pp. 8709-8717, 2001.

[19] T. Shimizu, T. Yamaguchi, F. Inoue, M. Inada and S. Shingubara, "AgNO3-Dependent Morphological Change of Si Nanostructures Prepared by Single-Step Metal Assisted Etching Method," Jpn. J. of Appl. Phy., vol. 51, no. 11S, pp. 11PE021-11PE024, 2012.

[20] P. Gorostiza, R. Diaz, M. A. Kulandainathan, F. Sandz and J. R. Morante, "Simultaneous platinum deposition and formation of a photoluminesccent porous silicon layer," J. Electroanal. Chem., vol. 469, no. 1, pp. 48-52, 1999.

[21] A. Backes and U. Shmid, "Impact of doping level on the metal assisted chemical etching of p-type silicon," Sens. Actuator B-Chem, vol. 193, pp. 883-887, 2014.

[22] N. Geyer, N. Wollschläger, B. Fuhrmann, A. Tonkikh, A. Berger, P. Werner, M. Jungmann, R. Krause-Rehberg and H. S. Leipner, "Influence of the doping level on the porosity of silicon nanowires 
prepared by metal-assisted chemical etching," Nanotechnology, vol. 26, no. 24, pp. 245301-245307, 2015.

[23] C. Chiappini, X. Liu, J. Fakhoury and M. Ferrari, "Biodegradable Porous Silicon Barcode Nanowires with Defined Geometry," Adv. Funct. Mater, vol. 20, pp. 2231-2239, 2010.

[24] S. Nichkalo, A. Druzhinin, O. Ostapiv and M. Chekaylo, "Role of Ag-catalyst morphology and molarity of $\mathrm{AgNo} 3$ on the size control of Si nanowires produced by metal-assisted chemical etching," Mol. Cryst.Liq. Cryst., vol. 674, no. 1, pp. 69-75, 2018.

[25] C. Chartier, S. Bastide and C. Levy-Clement, "Metal-assisted chemical etching of silicon in HFH2O2," Electrochim. Acta, vol. 53, no. 17, pp. 5509-5516, 2008.

[26] Y. Liu, G. Ji, J. Wang, X. Liang, Z. Zou and Y. Shi, "Fabrication and photocatalytic properties of silicon nanowires by metal-assisted chemical etching: effect of $\mathrm{H} 2 \mathrm{O} 2$ concentration," Nanoscale Res. Lett., vol. 7, no. 1, pp. 663-671, 2012.

[27] H. Han, Z. Huang and W. Lee, "Metal-assisted chemical etching of silicon and nanotechnology applications," Nano Today, vol. 9, no. 3, pp. 271-304, 2014.

[28] W. McSweeney, H. Geaney and C. O'Dwyer, "Metal-assisted chemical etching of silicon and the behavior of nanoscale maaterials as Li-ion battery anodes," Nano Res., vol. 8, no. 5, pp. 1395-1442, 2015.

[29] L. U. Vinzons, L. Shu, S. Yip, C.-Y. Wong, L. L. H. Chan and J. C. Ho, "Unraveling the morphological evolution and etching kinetics of porous silicon nanowires during metal-assisted chemical etching," Nanoscale Res. Lett., vol. 12, pp. 385-397, 2017.

[30] J. M. Duran and A. Sarangan, "Fabrication of ultrahigh aspect ratio silicon nanostructures using selfassembled gold metal-assisted chemical etching," J. Micro/Nanolith. MEMS MOEMS, vol. 16, no. 1, pp. 014502-8, 2017.

[31] B. S. Yilbas, B. Salhi, M. R. Yousaf, F. Al-Sulaiman, H. Ali and N. Al-Aqeeli, "Surface characteristics of silicon nanowires/nanowalls subjected to octadecyltrichlorosilane deposition and noctadecane coating," Scientific reports, vol. 6, p. 38678, 2016.

[32] M. L. Zhang, K. Q. Peng, X. Fan, J. S. Jie, R. Q. Zhang, S. T. Lee and N. B. Wong, "Preparation of Large-Area Uniform Silicon Nanowires Arrays through Metal-Assisted Chemical Etching," J. Phys. Chem. C, vol. 112, no. 12, pp. 4444-4450, 2008.

[33] E. Quiroga-González and H. Föll, "Fundamentals of Silicon Porosification via Electrochemical Etching," in Porous Silicon: Formation and Properties, CRC Press (Taylor \& Francis group), 2015.

[34] E. Quiroga-González, M. A. Juárez-Estrada and E. Gómez-Barojas, "Light enhanced metal assisted chemical etching of silicon," ECS Transactions, vol. 86, no. 1, pp. 55-63, 2018.

[35] Y. Li and C. Duan, "Bubble-regulated silicon nanowire synthesis surfaces by metal-assisted chemical etching," Langmuir, vol. 31, pp. 12291-12299, 2015. 
[36] K. Tsujino and M. Matsamura, "Helical nanoholes bored in silicon by wet chemical using platinum nanoparticles as catalyst," Electrochem. Solid-State Lett., vol. 8, no. 12, pp. C193-C195, 2005. 